\title{
ARTICULAÇÃO DO CONHECIMENTO ESPECÍFICO E ACADÊMICO COMO PROPULSOR DA QUALIDADE DO DESENVOLVIMENTO DOCENTE
}

\author{
A. L. H. T. BATTISTEL, S. M. ISAIA, D. TONÚS ${ }^{*}$ e T. L. GRIGOLO \\ Universidade Federal de Santa Maria- UFSM \\ dtonus@hotmail.com*
}

Artigo submetido em novembro/2013 e aceito em abril/2014

DOI: $10.15628 /$ holos.2015.1757

\begin{abstract}
RESUMO
Este artigo apresenta um recorte da pesquisa intitulada "Os movimentos da docência superior: especificidades nas diferentes áreas de conhecimento e sua influência na atuação docente", desenvolvida pelo Grupo de Pesquisa Trajetórias de Formação da Universidade Federal de Santa Maria (HFSM)/RS, que tem o objetivo de investigar as repercussões das áreas específicas de conhecimento da docência universitária em professores de ensino superior de uma instituição pública-IES pública, aprovada pelo CNPq relativo à bolsa $P Q$. Neste trabalho apresenta-se uma apreciação parcial dos dados coletados junto a nove professores do Centro das Ciências da Saúde da Universidade referida anteriormente, a partir da crítica de um dos eixos norteadores da pesquisa, o qual tem como objetivo analisar como os docentes investigados compreendem
\end{abstract}

os conceitos de conhecimento específico e acadêmico e como estes se relacionam ou se articulam na prática. Utilizou-se como pressupostos metodológicos a abordagem qualitativa de cunho narrativo proposto por Connelly e Clandinin (1995), Bolivar, Domingo e Fernández (2001 e 2004). A análise dos dados foi ancorada no referencial teórico proposto por Isaia e Bolzan e Maciel (2005,2006, 2008, 2010 e 2011). Os resultados evidenciaram que a articulação do conhecimento específico e acadêmico na prática pedagógica dos professores de ensino superior na área da saúde é atravessada pelos movimentos construtivos dos docentes, os quais estão relacionados com as trajetórias pessoal e profissional de cada sujeito, permeada pela especificidade da formação na área da saúde.

PALAVRAS-CHAVE: conhecimento específico, desenvolvimento docente, docência superior

\section{JOINT SPECIFIC KNOWLEDGE AND ACADEMIC AS THRUSTER QUALITY TEACHING DEVELOPMENT}

\begin{abstract}
This article presents part of a study entitled "The movements of the college teaching: specificities in different areas of knowledge and its influence on teaching practice", developed by the Research Group Trajectories Training, Federal University of Santa Maria (UFSM) / RS, which aims to investigate the effects of specific areas of knowledge of university teaching in college education teachers from a public - public IEs, approved by CNPq scholarship on the PQ. In this work we present a partial analysis of the data collected with nine teachers at Center of Health Sciences University said earlier, from the analysis of one of the guiding principles of research, which aims to analyze how teachers understand the investigated concepts and
\end{abstract}

academic expertise and how they relate or are articulated in practice. Was used as the methodological assumptions qualitative approach of narrative proposed by Connelly and Clandinin (1995), Bolivar, Domingo and Fernández (2001 and 2004). The data analysis was grounded in the theoretical framework proposed by Isaia and Bolzan and Maciel (2005, 2006, 2008, 2010 and 2011). The results showed that the combination of academic expertise and pedagogical practice of teachers of college education in the health field is crossed by constructive movements of teachers, which are related to personal and professional trajectories of each subject, permeated by the specificity of training in healthcare.

KEYWORDS: specific knowledge, teacher development, college teaching. 


\section{INTRODUÇÃO}

Este trabalho apresenta um recorte dos resultados da pesquisa intitulada "Os movimentos da docência superior: construções possíveis nas diferentes áreas do conhecimento" desenvolvida por um Grupo de Pesquisa de uma Universidade pública no interior do estado, que tem como objetivo de investigar as repercussões das áreas específicas de conhecimento nos movimentos construtivos da docência universitária em professores de ensino superior de uma instituição pública. Neste trabalho, apresentamos uma análise parcial dos achados referentes às entrevistas narrativas realizada com professores do Centro de Ciências de Saúde da UFSM.

Para Isaia e Bolzan (2008), os Movimentos da Docência Superior (MDS) são caracterizados como uma sequencia não linear e são construídos a partir das experiências vivenciadas durante a trajetória docente, sendo levados em consideração aspectos pessoais, profissionais e institucionais e como estes acontecimentos são interpretados. A partir das pesquisas realizadas as autoras puderam inferir quatro principais movimentos: Preparação para a Carreira Docente, Entrada Efetiva no Magistério Superior, Marca da Pós-Graduação na Docência e Professoralidade Docente.

A plena consciência da docência superior surge da capacidade de compreender e interligar as especificidades das três dimensões: Conhecimento específico, aquele relativo aos conhecimentos básicos de uma determinada área, responsável pela compreensão do seu processo de construção; Conhecimento pedagógico geral, aquele relativo aos objetivos, metas, estratégias pedagógicas e institucionais e o Conhecimento pedagógico do conteúdo, que integra o conhecimento específico com o pedagógico e que possibilita ao professor conceber os propósitos de ensinar determinada matéria e as estratégias importantes e necessárias para que os alunos aprendam. (ISAIA e BOLZAN, 2008).

A carreira docente é influenciada pelas experiências vividas, auxiliando a construção do ser professor, processo no qual ocorre o enfrentamento diário dos conhecimentos advindos da profissão de origem e da profissão docente, que se articulam em prol de um ensino de qualidade e eficaz. (ISAIA E MACIEL (2011). E ainda, um processo de aprendizagem permanente no exercício continuado da docência, "que acompanha toda a trajetória do professor, indicando sua incompletude como ser humano e como docente." (ISAIA e BOLZAN, 2008).

Assim, de acordo com Isaia e Bolzan (2008) o primeiro movimento, caracterizado como a Preparação para a Carreira Docente, envolve experiências que ocorrem desde o ensino médio, passando por monitorias, participações em projetos, residências, especializações, vivência como professor substituto, enfim, todas as experiências vividas durante o processo de vir a se tornar docente.

Já o segundo movimento, a Entrada Efetiva no Magistério Superior, é compreendido como uma oportunidade de entrada no mercado de trabalho docente. A grande maioria das pessoas entrevistadas relata não ser esta uma escolha efetivamente buscada, exceto alguns docentes referem ter consciência da escolha planejada da docência como profissão. Nesse movimento Isaia e Bolzan (2008), evidenciaram algumas percepções por parte dos docentes, dentre elas, a solidão pedagógica, insegurança, dificuldades relacionadas ao conteúdo ministrado, falta de domínio para estar no papel de docente de ensino superior. Ainda, durante 
esse período da trajetória, pode ocorrer a valorização acentuada dos conteúdos específicos, referentes aos assuntos abordados durante a disciplina como conceitos, definições e tópicos gerais.

Para Bolzan, Isaia e Maciel (2013), o processo de aprendizagem da docência implica na aquisição de saberes que a atividade docente proporciona a partir do aprimoramento profissional, dos desafios e das escolhas e decisões vivenciadas em sala de aula. As autoras ressaltam que, a partir das pesquisas desenvolvidas, pode-se observar que, um dos grandes obstáculos para os docentes está em diferenciar o conhecimento especifico e acadêmico repercutindo dessa forma, na formação acadêmica.

Assim, acredita-se que, no inicio da carreira docente, o professor, influenciado por todos os aspectos já citados, principalmente pela inexperiência, pode tornar o conhecimento específico o foco das suas aulas, esquecendo em muitos momentos, de estimar o conhecimento pedagógico, tão relevante para os processos de ensino e de aprendizagem. Isaia e Bolzan (2008) ressaltam que, é necessário além do conhecimento específico o investimento no conhecimento pedagógico, tais como a sensibilidade frente ao aluno, às relações interpessoais, a valorização das experiências e da participação compartilhada, a articulação teórica e prática, entre outros aspectos que se tornam fundamentais.

Conforme Isaia e Maciel (2011) tornar-se professor perpassa pela profissão de origem, pelos conhecimentos específicos e pelo domínio do objeto de estudo dessa profissão. Ser docente envolve além do conhecimento especifico, da prática vivenciada, a articulação destes conhecimentos aos novos cenários que se apresentam na educação. Envolve o vínculo entre docente e discente, as relações de respeito, novas tecnologias e metodologias de ensino, reflexão, a qualificação continuada, contribuindo para um ambiente de aprendizagem colaborativa.

Já o terceiro movimento está ligado às Marcas da Pós-graduação e as experiências que este momento pode proporcionar aos docentes. A inserção em uma pós-graduação, seja ele um mestrado ou doutorado implica em possibilidades de ascensão na carreira docente, visto que, atualmente as Instituições de Ensino Superior- IES possuem como critério de seleção tais requisitos. Além disso, a possibilidade de cursar uma pós-graduação é compreendida como um momento de novos aprendizados enriquece a formação, a qualificação e o aprimoramento docente.

O último movimento da docência é a Professoralidade Docente, definida por Isaia e Bolzan (2008) como o momento em que o docente compreende que o domínio do conhecimento, saberes e fazeres não são suficientes. Existe uma reflexão e apropriação, resultados da experiência docente, que enfatizam a sensibilidade, atitudes, valores, como componentes indispensáveis ao processo de ensinar e aprender.

Marcelo Garcia (2009) em suas pesquisas evidencia que, as respostas positivas dos alunos em sala de aula dependem da relação destes, com o professor, que deve buscar ser eficiente e manter essa eficiência, demonstrando sua capacidade de estar atento as transformações, ao perfil de cada turma, atualizado quanto aos conteúdos e a forma como serão ensinados. 0 desafio dos professores se configura na necessidade de acompanhar o processo de aprendizagem dos alunos que, hoje, se transformam de forma rápida e constante, acarretando maior envolvimento e esforço por parte do professor para acompanhar essas mudanças. 
Partindo então destes movimentos, a pesquisa teve como objetivo investigar as especificidades dos movimentos da docência, tendo em vista a área de conhecimento dos sujeitos envolvidos. Este artigo apresentará um recorte da pesquisa referente aos dados coletados junto a professores da área da saúde, visando discutir como eles articulam o conhecimento específico e acadêmico e o reflexo dessa articulação em seu desenvolvimento docente.

\section{METODOLOGIA}

O caminho metodológico adotado seguiu os pressupostos da abordagem qualitativa de cunho narrativo (CONNELLY; CLANDININ, 1995; MCEVAN,1998; BOLIVAR; DOMINGO e FERNÁNDEZ, 2001), pelo entendimento de que as entrevistas narrativas além de ser um método de formação, provoca no sujeito pesquisado reflexão das experiências e aprendizagens bem como a análise de seu papel em sua própria história (SOUZA, 2006). Sendo assim, torna-se um instrumento valioso para investigar as especificidades dos movimentos da docência, visto que retratam de forma real os sentimentos, opiniões, valores das pessoas pesquisadas.

O instrumento utilizado para a coleta dos dados foi a entrevista narrativa, registrada em meio digital (gravação em MP3), a qual foi guiada por uma Matriz Categorial, com base em eixos investigativos que se desdobravam em indicadores que as nortearam. Para este trabalho foi selecionado um dos eixos denominado Articulação do Conhecimento Específico e Acadêmico, que continham dois indicadores: Diferenciação entre o conhecimento específico da área e o conhecimento acadêmico trabalhado em aula e Articulação entre o conhecimento específico e o conhecimento acadêmico trabalhado em aula.

Foram analisadas as entrevistas de nove docentes do Centro de Ciências da Saúde de uma universidade pública do interior do estado do Rio Grande do Sul, cujos participantes foram assim distribuídos: um professor dos cursos de Enfermagem, Farmácia e Fisioterapia, dois professores do curso de Odontologia, e quatro professores do curso de Medicina. Os dados foram analisados por meio da Análise Textual Discursiva proposta por Bauer; Gaskell (2004) e Moraes (2003), por ser "uma abordagem concebida como um processo de auto-organização de produção de novas compreensões em relação aos fenômenos que examina". (MORAES, 2003, p. 209). A partir dos quadros de analise das entrevistas, ficaram evidenciados os principais marcadores encontrados e as especificidades dos movimentos da docência.

Para garantir o anonimato dos professores pesquisados, eles foram sinalizados pelas letras do alfabeto na sequencia de $\mathrm{A}$ a $\mathrm{H}$, conforme a ordem em que suas narrativas vão sendo apresentadas, sem demarcar a área de formação básica.

\section{RESULTADOS E DISCUSSÕES}

De acordo com Isaia (2005, 2008), ao possibilitar a experiência de dar voz aos participantes, é possível uma retomada das vidas profissionais, levando em consideração aspectos relevantes dessa trajetória, sendo, portanto, um objeto de reflexão na busca por aperfeiçoamento e transformação. Ainda de acordo com a autora, as narrativas docentes fornecem dados que possibilitam uma compreensão mais detalhada dos movimentos da docência, sendo estas, interpretadas e reescritas de forma que possam ser analisadas. 
Os professores investigados encontram-se em distintos Movimentos da Docência Superior, que conforme a classificação de Isaia e Bolzan (2008), foram desta forma configurados: dois participantes estão no Movimento de Entrada Efetiva no Magistério Superior, três se encontram no que se classifica como Marca da Pós-Graduação na Docência, e quatro professores no Movimento Professoralidade Docente.

Tradicionalmente a formação de professores que atuam na área da saúde tem ocorrido no exercício da profissão. Não raro a escolha pela docência tem sido circunstancial. A formação inicial é pautada na especificidade da profissão e busca pelo conhecimento técnico-científico que possa garantir segurança no domínio do conteúdo específico a ser ensinado. A aprendizagem ao longo da vida, portanto ocorre na formação em serviço, no entrejogo pautado na própria formação e na formação e novos profissionais da saúde. De modo que, o bacharelado garante a formação na área específica, mas não a preparação para a docência.

A análise dos dados relativos ao eixo investigado Articulação entre o conhecimento específico e acadêmico, ficou prejudicada em relação ao indicador que busca elucidar a Diferenciação entre o conhecimento específico da área e o conhecimento acadêmico trabalhado em aula, visto que os professores pesquisados apresentaram dificuldade em identificar o conceito de conhecimento da área específica e, por conseguinte a relação deste, com as experiências práticas do trabalho. Este dado explicita a importância e necessidade de reflexões em relação ao campo e núcleo de conhecimento ${ }^{1}$ de cada profissão, devido ao impacto na definição do objeto de estudo da profissão e sua repercussão na formação acadêmica e na consequente reprodução de um perfil profissional com as mesmas dificuldades de delimitar seu núcleo de conhecimento. Considerando que o Sistema Único de Saúde preconiza o trabalho em equipe interdisciplinar, tal definição é de suma importância para a realização de um trabalho integrado e eficaz, dado que para melhor atuação em equipe interdisciplinar de saúde é fundamental o conhecimento e delimitação da profissão escolhida, bem como dos demais participantes da equipe.

Os excertos a seguir são reveladores em relação à falta de clareza na diferenciação entre os conhecimentos específico e pedagógico, remetendo ao segundo o significado de prática, conforme a fala abaixo:

\footnotetext{
"Sim, porque no Curso de Odontologia a gente tem dois tipos de aula: teórica e prática. As teóricas geralmente são aulas expositivas, e os conhecimentos das aulas teóricas a gente trabalha nas aulas práticas mesmo, com atendimento de pacientes." (Professor A).
}

“[...] eu vivi isto dentro do conselho, então eu trago uma bagagem vivida que complementa e ela dá muito mais sentido ao que está posto como conhecimento que outro docente que não tem toda esta trajetória e que vai dar esta disciplina, vai ter só o que os documentos tem, falar o que os documentos tem[...]"(Professora B).

"Bom, primeiro porque eu não dou uma aula teórica em sala de aula, eu parto da vivência da realidade do aluno, onde ele está inserido. Então não é porque eu

\footnotetext{
${ }^{1}$ Campo e núcleo de conhecimento são definidos respectivamente, como um conjunto de saberes e práticas comuns às várias profissões ou especialidades do setor saúde e campos que articulam os diferentes saberes e práticas exclusivas de cada profissão. (SOUSA CAMPOS, 2000).
} 
tenho todo um plano, eu tenho um plano mas tu fazes um plano de ensino, um plano de uma aula, mas muito antes de um plano é o aluno, quando ele está lá na realidade, então primeiro eu faço visita no serviço de saúde pública. Eu faço vivencias com eles, então eles visitam os serviços."( Professora C).

Esse fato reforça o que Pimenta e Anastasiou (2002) referem ao relatar que, apesar do tempo de experiência dos professores, muitos ainda demonstram algum despreparo ou desconhecimento quanto às questões relacionadas ao processo de ensino e aprendizagem. Ainda nesse sentido, Powaczuk (2012), ressalta que, o professor necessita articular tais conhecimentos, tanto o específico quanto o acadêmico, visto que, o domínio do conhecimento acadêmico qualifica o desempenho e o trabalho docente. Outros participantes demonstram essa preocupação a partir de seu relato:

"É, é um desafio hoje tu fazeres isso. Eu acho que eu me coloco como um facilitador na minha área, eu não me coloco mais como um professor dono do conhecimento. $O$ que se tem é uma grande paixão pela área e uma leitura constante, porque a produção é muito grande, e essa produção eu tento passar para o aluno, mas tento passar a empolgação". (Professor D).

Bolzan, Isaia e Maciel (2013) corroboram com narrativa do Professor D, quando refere que o foco na formação de professor não pode estar restrito a organização dos conteúdos e seus conceitos, mas também na mobilização dos sujeitos, na socialização, reflexão, motivação, possibilitando novas aprendizagens. Como também se pode ver na fala do Professor E:

“Medicina é uma coisa diferente, tem que ser um ensino tecnicista porque você
não pode deixar o aluno inventar, ser criativo em termos de cirurgia
principalmente. Inventar uma técnica cirúrgica e matar o cara. Então não tem
como tu fazer isso (...). E eu tinha dito pra eles que não dava para ensinar
cirurgia por seminários. Não dá principalmente cirurgia porque eles têm que ver
imagens. Eles têm que saber qual é a imagem, o que vai ser retirado e o que vai
ter que ser anastomosado, o que vai ser feito." (Professor E).

Os dados evidenciaram que a distinção entre os conceitos de conhecimento específico e conhecimento acadêmico gerou respostas diferenciadas. Além disso, foi possível verificar que os professores com maior tempo de docência, apesar da prática e da qualificação stritu sensu em nível de mestrado e doutorado, ainda evidenciam falta de apropriação das questões pedagógicas, pouco discutidas no âmbito dos cursos de bacharelado em saúde. De outra parte os dados evidenciaram que os professores enquadrados no movimento Entrada Efetiva no Magistério Superior são os que melhor compreendem essa diferença, o que leva a inferir que atualmente os professores que iniciam a carreira docente apresentam uma formação que possibilita uma maior compreensão e percepção da relevância do conhecimento acadêmico para o desenvolvimento profissional docente. Embora cheguem à docência com maior qualificação acadêmica e uma menor experiência da prática profissional, como se pode ver no excerto a seguir:

"No doutorado, pelo currículo que ele tem, ele é selecionado. Ele publica mais uns três artigos, defende sua tese e está com o currículo bom para tentar seleção para professor. Daí ele passa a ser docente sem ter uma vivência na atividade. Se isso é bom ou ruim só o tempo dirá. Eu acho que isso é ruim. Eu preciso saber para poder ensinar. Eu preciso estabelecer uma relação entre o 
conhecimento puro cientifico e a sua aplicação na prática da atividade terapêutica, da conduta terapêutica, e eu preciso executar, meu estudante de odontologia precisa saber preparar uma cavidade, ele precisa saber fazer o acesso cirúrgico, coisa que ele aprendeu na graduação e passou cinco, seis anos só no mestrado e doutorado e o treinamento nesse período praticamente não ocorreu." (Professor A).

No tocante ao segundo indicador, Articulação entre o conhecimento específico $\boldsymbol{e} \boldsymbol{o}$ conhecimento acadêmico trabalhado em aula, alguns docentes referem à importância da trajetória pessoal no processo de formação e compreendem a articulação entre o conhecimento específico e o acadêmico trabalhado em aula a partir da relação teoria-prática.

“(...) é naquela exemplificação e na forma de dizer as coisas também, por exemplo, na disciplina lá do primeiro semestre que é a de política e saúde, todas as leis do SUS, tudo que está sistematizado como informação sobre política e saúde, tudo o que o ministério disponibiliza lá e tudo mais, existe isto, mas para trazer isto eu levo com a vivência, olha gente eu estive no conselho de saúde, portanto lá foi visto isso e isto, eu estive na $10^{\circ}$ conferência de Saúde, uma conferência isto e isto eu vivi coisas que complementam e que só dão sentido, dão muito mais sentido aquilo que está sistematizado como conhecimentos: os princípios do SUS, por eu poder dizer que eu vivenciei aquilo, aquele controle nacional, numa conferência nacional e que é muito importante é muito melhor do que eu falar só o que é controle social." (Professora B).

Outros professores usam metodologias variadas como estratégia para articular o conhecimento específico ao conhecimento acadêmico de modo a oferecer suporte teórico e prático quanto aos conteúdos discutidos em sala de aula, conforme relato da Professora C:

“(...) Pode ir se utilizando do portfólio e outra eles fazerem... fazem uma síntese escrita a cada aula e me entrega na próxima. Leem e tem que fazer uma avaliação teórica e também de como a forma que a gente trabalhou. Então eu trabalho na minha aula o teórico, o prático e também lá na prática os campos teóricos, então sempre fazendo essa relação. E no momento em que eles estão fazendo o portfólio eles têm que estar fazendo uma discussão constante daquilo que foi visto na aula teórico prática co-relacionando com o referencial teórico e se auto- avaliando o que conseguiram avançar (...)"( Professora C).

Isaia (2010) relata que, existe uma dificuldade por parte dos docentes em se perceberem como especialistas dos conteúdos específicos, mas também, profissionais da educação.

“(...) O grande cuidado que tem que se ter quando tu tens uma especialidade e você vai trabalhar a formação básica em que eu não estou formando uma ginecologista, um ginecologista, eu estou é participando de uma formação muito ampla e complexa que é formar uma pessoa, um cidadão, uma cidadã médica ou médico. Então é lógico que faço abordagens de correlação onde eu coloco todas as possibilidades as vezes que o meu conhecimento permite dentro das várias áreas. Então por exemplo, eu não foco exclusivamente aquela especialização da área em que eu me formei, é abordado tudo na clínica, cirurgia, enfim(...)" (Professor F). 
O que também pode demonstrar uma preocupação por uma formação generalista preconizada pelas diretrizes curriculares para a área da saúde, que vem ao encontro do desejo de formar um profissional apto a atuar na perspectiva da atenção integral à saúde. Como elucida a fala do Professor G:

(...) eu acho que aos poucos a gente ta perdendo essa integração total dentro da nossa especialidade porque cada vez mais estão se formando especialistas numa área específica e eles apesar de terem conhecimento básico geral, eles começam a se afastar das outras áreas que eles não estão mais aceitos ali, porque o ginecologista romântico que conseguiria tratar, ou melhor, que tratar promover a saúde da mulher está se extinguindo cada vez mais, está começando a ter o que faz infantotuberal, o colposcopista, quem faz transgenital inferior, quem faz mamas só. (Professor $\mathrm{G}$ ).

Contudo, essa percepção faz parte do processo de constituir-se docente e dos movimentos da docência já discutidos anteriormente. Esse processo envolve o desenvolvimento pessoal, profissional, possibilitados a partir de experiências como ações formativas orientadas e interação com outros professores e estudantes. (MARCELO GARCIA, 2009). Alguns participantes da pesquisa percebem esse processo, conforme se pode ver no relato a seguir:

“(...) na verdade a experiência da gente vale muito para a sala de aula, então a gente em cima da vivencia e da experiência do hospital é que a gente monta este material que vai ser levado para a sala de aula em cima do conteúdo programático que está no papel (...) isto varia de docente para docente, o conteúdo está ali, mas cada docente vai dar aquele conteúdo de um jeito, de acordo com o seu preparo, experiência (...)". (Professor H).

O desenvolvimento profissional docente é considerado como um processo em constante transformação, que evolui ao longo da carreira, influenciado pela formação básica, prática profissional, contexto em que o professor está inserido, valores, crenças e formação continuada. Assim, a partir das vivências, reflexões, discussões, metodologias utilizadas e até mesmo, do tempo de docência, pode-se compreender como cada docente desenvolve-se enquanto profissional e como esse desenvolvimento influencia na formação dos acadêmicos.

Os dados analisados revelam que os professores pesquisados apresentam dificuldade em identificar o conceito de conhecimento da área específica e a relação deste com as experiências práticas do trabalho. $O$ dado é relevante e explicita a necessidade de reflexões em relação ao conhecimento específico de cada profissão, visto a relevância para a definição do objeto de estudo, o que repercute na formação discente reproduzindo o profissional com capacidade ou não para delimitar seu núcleo de conhecimento.

Conforme Isaia (2006, p.375) "o desenvolvimento profissional e formação se entrelaçam e um intricado processo, a partir do qual o docente vai se constituindo pouco a pouco. O saber e o saber fazer são conquistados ao longo da carreira." Assim, acredita-se que, o desenvolvimento profissional docente, requer uma trajetória onde o docente perpasse pelos movimentos já citados, onde estes possam influenciar e provocar reflexões capazes de transformar a prática da docência.

Ainda para Marcelo Garcia (2009), o desenvolvimento profissional docente concretiza-se a partir do momento em que existe uma troca entre pares, entre colegas ou profissionais da área, 
existindo, portanto, discussões, grupos de estudo e questionamentos. Todas estas ações voltadas para uma analise da trajetória docente servem como suporte e alavancam o repertorio de conhecimentos teóricos e práticos dos professores. Contudo, observa-se que, o ambiente da educação superior, continua em muitos momentos sendo solitário, havendo poucos momentos de trocas e de compartilhamento de experiências.

Santos (2011), ressalta que, o grande desafio dos docentes está na compreensão de que as reflexões e a articulação dos saberes científicos e pedagógicos contribuem para a o seu desenvolvimento profissional e dos seus pares. Instituir momentos de capacitação em grupo torna-se relevante para as Instituições de Ensino Superior, além de ser uma estratégia de aperfeiçoamento onde todos são beneficiados, professores, alunos e IES. Em especial no que se refere aos professores da área da saúde, tendo em vista sua formação tecnicista e o desconhecimento dos conhecimentos pedagógicos necessários à prática docente.

O autor colabora com essa ponderação reforçando que, a superação do isolamento profissional ocorrerá no momento em que os docentes adotarem uma perspectiva de trabalho em equipe, revendo as estratégias de ensino e criando novas opções metodológicas. A partir dessa nova relação, união e fortalecimento dos grupos poderão se constituir novas aprendizagens, que culminarão em desenvolvimento profissional.

\section{CONSIDERAÇÕES FINAIS}

O desenvolvimento profissional docente é considerado como um processo em constante transformação ocorridas ao longo da carreira, influenciado pela formação inicial e continuada, pela prática profissional da área específica e do exercício da docência, além do contexto em que o professor está inserido, seus valores, crenças. Assim, a partir das vivências, reflexões, discussões, metodologias utilizadas e até mesmo, do tempo de docência, pode-se compreender como cada docente desenvolve-se enquanto profissional e como esse desenvolvimento influencia na formação dos acadêmicos.

A partir dos resultados encontrados, pode-se constatar que a articulação do conhecimento específico e acadêmico na prática pedagógica dos professores de ensino superior na área da saúde é atravessada pelos Movimentos da Docência Superior, os quais estão relacionados com as trajetórias pessoal e profissional de cada sujeito, permeada pela especificidade da formação na área da saúde.

Foram analisados dois indicadores do eixo Articulação do Conhecimento Específico e Acadêmico. Em relação ao indicador Diferenciação entre o conhecimento específico da área e o conhecimento acadêmico trabalhado em aula, observa-se que as maiorias dos docentes apresentam dificuldade em identificar o conceito de conhecimento da área específica, bem como não identificam a diferença entre os conceitos de conhecimento específico e acadêmico. $O$ dado é relevante e explicita a necessidade de reflexões em relação ao conhecimento específico de cada profissão, visto a relevância para a definição do objeto de estudo, o que repercute na formação discente reproduzindo o profissional com capacidade ou não para delimitar seu núcleo de conhecimento. Conhecimento este fundamental para uma adequada participação em equipe de saúde interdisciplinar. 
Na maioria dos casos não há uma reflexão sobre o conhecimento acadêmico e sua importância para a prática pedagógica, o que leva a reflexão sobre o processo formativo dos docentes da área da saúde que, conforme já foi discutido, não são preparados para atuar na docência.

Esse resultado interfere de forma significativa no outro indicador analisado, Articulação entre o conhecimento específico e o conhecimento acadêmico trabalhado em aula, uma vez que a não diferenciação de um conceito do outro, repercute na incapacidade de realizar essa articulação e, por conseguinte na articulação desses conhecimentos como propulsor da qualidade do desenvolvimento docente e qualificação da formação pretendida.

Acredita-se que para os professores da área da saúde é importante que além de uma sólida formação básica, que como eles afirmam é tecnicista, haja uma formação pedagógica. Que as Instituições de Ensino Superior, possam acolhê-los e auxiliá-los a investir na formação continuada, seja por meio de capacitações sistemáticas, seja por meio de uma ambiência que favoreça a aprendizagem pedagógica compartilhada a fim de ampliar a qualidade de seu desenvolvimento profissional docente.

\section{REFERENCIAS}

1. BAUER, M. W.; GASKELL, G. Pesquisa qualitativa com texto, imagem e som: Um manual prático. 3. ed. Petrópolis, RJ: Vozes, 2004.

2. BOLÍVAR, A. DOMINGO, J.; FERNÁNDEZ, M. La investigación biográfica-narrativa em educación. Madrid: La Muralla, 2001.

3. CONNELLY y CLANDININ. Relatos de experiência e investigación narrativa. In: LARROSA; ARNAUS; FERRER et al. Déjame que te cuente. Barcelona: Alertes, 1995.

4. BOLZAN, D. P. V.; ISAIA, S. M. A.; MACIEL, A. M. R. Formação de professores: a construção da docência e da atividade pedagógica na Educação Superior. Rev. Diálogo Educ., Curitiba, v. 13, n. 38, p. 49-68, jan./abr. 2013.

5. . Ciclos de vida profissional docente: delineamento teórico-metodológico específico para professores do ensino superior. In: ALONSO, Cleuza M.M.C. (org.). Reflexões sobre políticas educativas. I Encontro Internacional de Pesquisadores de Políticas Educativas. Santa Maria, Universidade Federal de Santa Maria e Universidade la Republica Montevideo, AUGM, 2005, p.35-44.

6. - Desafios à docencia superior: pressupostos a considerar. In: RISTOFF, D; SEVEGNANI, P. Docência na Educação Superior. Brasilia:INEP, 2006.

7. Aprendizagem docente: sua compreensão a partir das narrativas de professores. In: TRAVESSINI, C.; EGGERT, E.; PERES, E.; BONIN, I. Trajetórias e processos de ensinar e aprender: práticas e didáticas. Porto Alegre: EDIPUCRS, 2008.

8. ISAIA, S; BOLZAN. D.P.V. Compreendendo os movimentos construtivos da docência superior: construções sobre pedagogia universitária. In: Linhas Críticas.v.14, n.26, p. 43-58. Brasília, DF: UnB, 2008.

9. ISAIA, S.M. A. Relatório final de Pesquisa. CNPq, 2010.

10. ISAIA, S.M.A.; MACIEL, A.M.R. Comunidades de práticas pedagógicas universitárias em ação: 
construindo a aprendizagem docente. Imagens da Educação, v. 1, n. 1, p. 37-47, 2011.

11. ISAIA, S. M. A. Os movimentos da docência superior: construções possíveis nas diferentes áreas de conhecimento. Projeto de Pesquisa PQ-CNPq, 2010- 2012.

12. MARCELO; G. Desenvolvimento Profissional Docente: passado e futuro. Sísifo -revista de ciências da educação $\cdot n$. o $8 \cdot$ jan/abr 2009.

13. MORAES, R. Uma tempestade de luz: a compreensão possibilitada pela análise textual discursiva. Ciência \& Educação, v.9 n.2, 2003. p.191-211.

14. MCEWAN, H. Las narrativas en el estudio de la docência. In: McEWAN y EGAN (comps.) La narrativa en la enseñanza, el aprendizaje y la investigación. Buenos Aires: Amorrortu, 1998.

15. PIMENTA, S. G.; ANASTASIOU, L. G. C. Docência no ensino superior. São Paulo: Cortez, 2002.

16. POWACZUK, A.C.H. Movimentos da professoralidade: a tessitura da docência. Tese de Doutorado. Centro de Educação, Universidade Federal de Santa Maria-RS, 2012.

17. SANTOS, E. G. A dinâmica das ações extensionistas nos processos formativos de professores da educação básica: a tessitura de redes de relações entre escola e universidade. Projeto de Tese. Universidade Federal de Santa Maria (UFSM, RS). Programa de Pós-Graduação em Educação, 2011.

18. SOUZA, E.C. A arte de contar e trocar experiências: reflexões teórico-metodológicas sobre historia de vida em formação. In: Revista Educação em questão, PPGE/CCSO/UFRN, vol 25, n.11, jan/abril, 2006.

19. SOUSA CAMPOS, Gastão Wagner de. Saúde pública e saúde coletiva: campo e núcleo de saberes e práticas. Ciência \& Saúde Coletiva [On-line] 2000, 5 (abril-junho): [Data deconsulta:9/agosto/2013]DisponívelEm:<http://www.redalyc.org/articulo.oa?id=6305020 2> ISSN 1413-8123. 